\title{
Arenas for implicit education: Looking at leftovers
}

\author{
Giuseppina Marsico ${ }^{\mathrm{a} 1}$, Min $\mathrm{He}^{\mathrm{b}}$, Jaan Valsiner \\ ${ }^{a}$ University of Salerno \\ ${ }^{b}$ East China Normal University \\ ${ }^{c}$ Centre for Cultural Psychology, Aalborg University
}

\begin{abstract}
In schools and kindergartens much of education happens in "secondary places" locations in the territory of the educational institution that are not meant for direct instruction purposes, but where all participants necessarily encounter in their daily lives. We analysed entrances, corridors and staircases from the perspective of semiotic encoding of educational values and objectives into the "secondary places", using, as evidence, ethnographic experiences from Chinese kindergartens and schools. We demonstrate that such encoding completes the fullness of cultural organisation of the environment guaranteeing the redundancy of the educational directions of the messages.
\end{abstract}

Keywords: educational spaces, ornaments, China, education, corridors

\section{Introduction}

Schools are strange places. They separate both the pupils from the community and simultaneously unite them with it. They are there to cut the connection of the pupils with that of their past - by introducing authoritative knowledge not immediately available on a daily basis (Valsiner, 2003). At the same time, this introduced formal education is of crucial relevance to the local community - it provides for innovations that cannot be produced on local grounds.

Obviously, the usual focus of educators is on the primary process of schooling - which happens in the classrooms. But there is also a secondary arena for the education system - the whole symbolic structure of the school

1 Dipartimento di Scienze Umane, Filosofiche e della Formazione (DISUFF), Università di Salerno, via Giovanni Paolo II, 132, 84084 Fisciano, SA, Italia; gmarsico@unisa.it 
or kindergarten that is the full environment for pupils and teachers every day. How are these "in-between" spaces of educational settings filled with educational social suggestions?

\section{Walking through the Chinese schools}

During our recent stay in Shanghai (October 2017), we visited kindergartens and primary schools in urban areas and in the countryside ${ }^{2}$. A group of Chinese professors, $\mathrm{PhD}$ and MA students, and few internationals scholars were welcomed in Chinese educational institutions ${ }^{3}$. We were accompanied into the schools during the regular school hours by the principals or professors, who told us what kind of activities the school carried out, the prizes won, the competitions in which the school took part, and all the narratives about the school's pedagogical credo. We were also fortunate to be invited to assist in some classes, to observe what was going on in the different settings (from the old Chinese calligraphy room, to the musical lab, to the everyday activity room to the very impressive library). We saw the architectural structures and all the educational equipment necessary to achieve their academic goals. Furthermore, we were the privileged audience of a theatre performance given by the students and attended various meetings with teachers, coordinators, and principals where specific didactic interventions were discussed. We were asked to take part in the general debate and contribute our thoughts, albeit limited, on our understanding of the Chinese contemporary school system.

During this field work we were free to walk into the classrooms and observe the educational activities. We even joined the staff and pupils to have tea and lunch at the school. Yet the most interesting part was "just" walking through the Chinese schools and being exposed to the richness of the educational messages that were present almost everywhere, even in places like corridors and stairs usually considered passage zones without any educational significance.

This was the field trip of our international seminar Coordinating Individual and Collective: From China to The World organised by the Faculty of Education and the Department of Psychology of East China Normal University.

3 The current Chinese school system is called the Modern System and it is based on the education reform of 1978. The year's distribution (from primary to high school) is the following: Preschool from 3 to 6 years, Primary School from 6 to 12; Middle School from 12 to 15 and High School from 15 to 18. According to the Chinese Education Ministry's statistics (2016) for Basic Education, 55\% of children are in private preschools, while most primary school students attend public schools. 
In the Chinese educational landscape, corridors and stairs occupy a valued position. They are not treated as just places for moving from one place to another, but as architectural educational devices (Figure 1, 2 and 3).

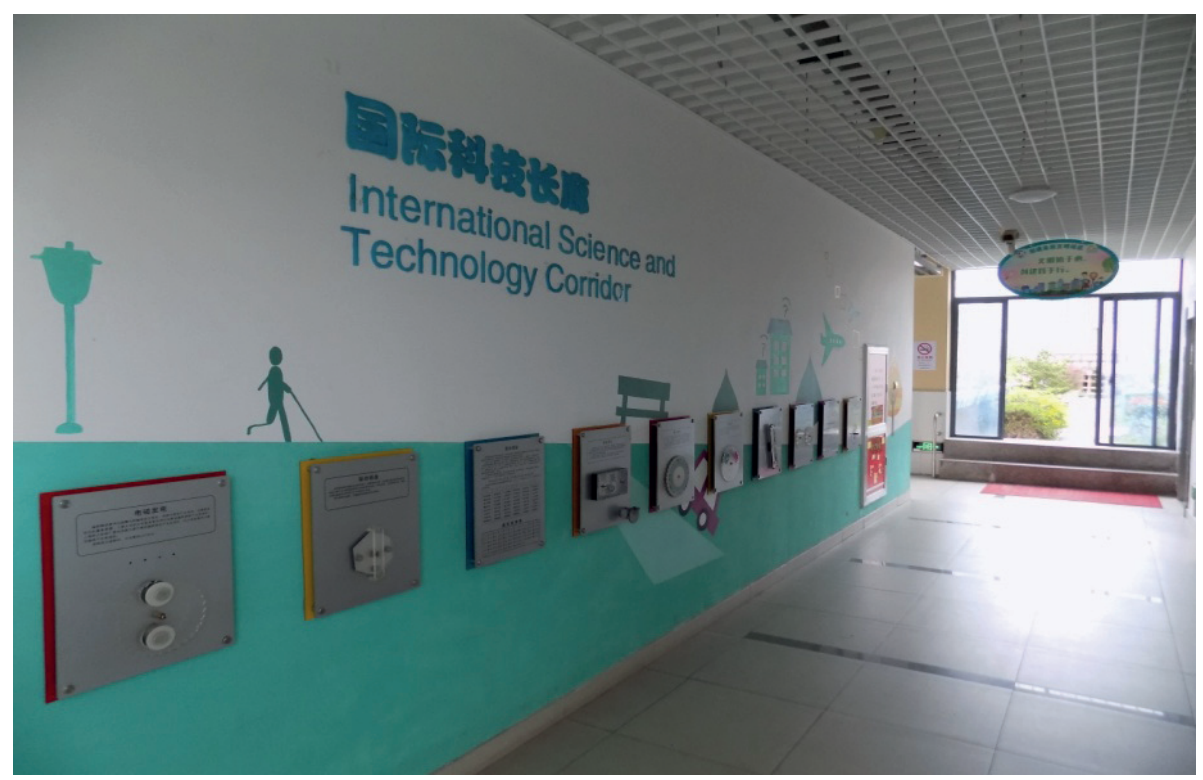

Figure 1. Corridor in a middle school in Shanghai

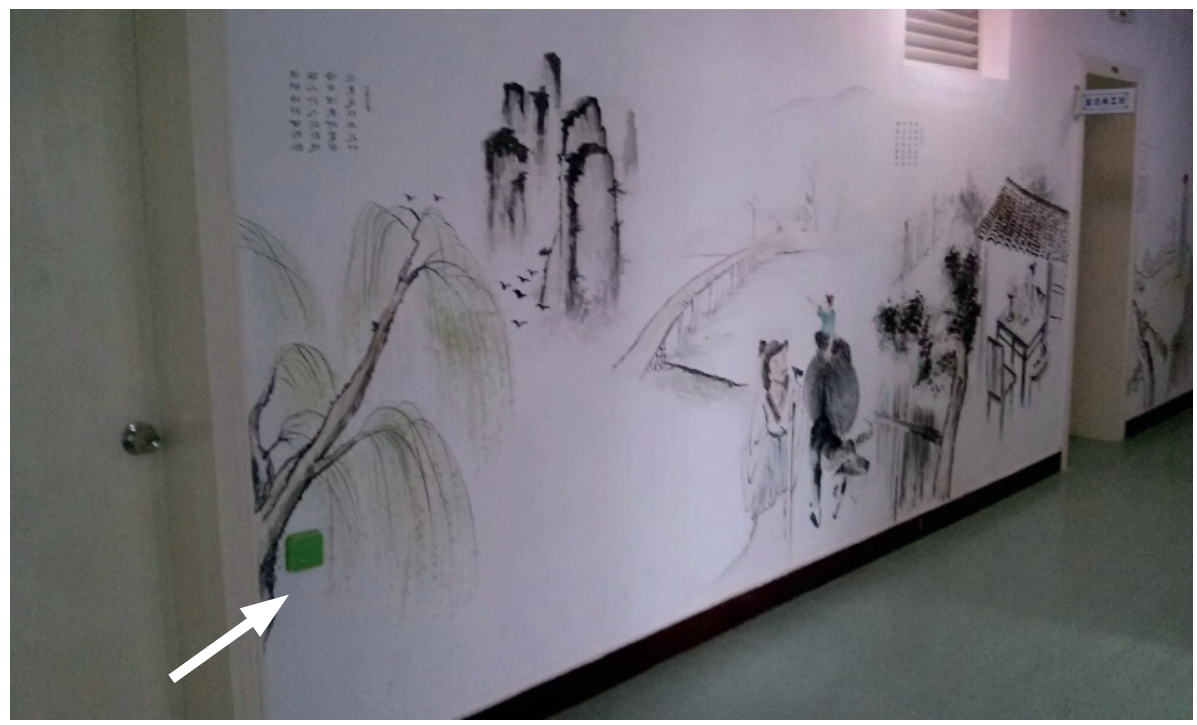

Figure 2. Corridor in a Kindergarten in Shanghai (affiliated to the East China Normal University). Photo by Marsico, 2017 


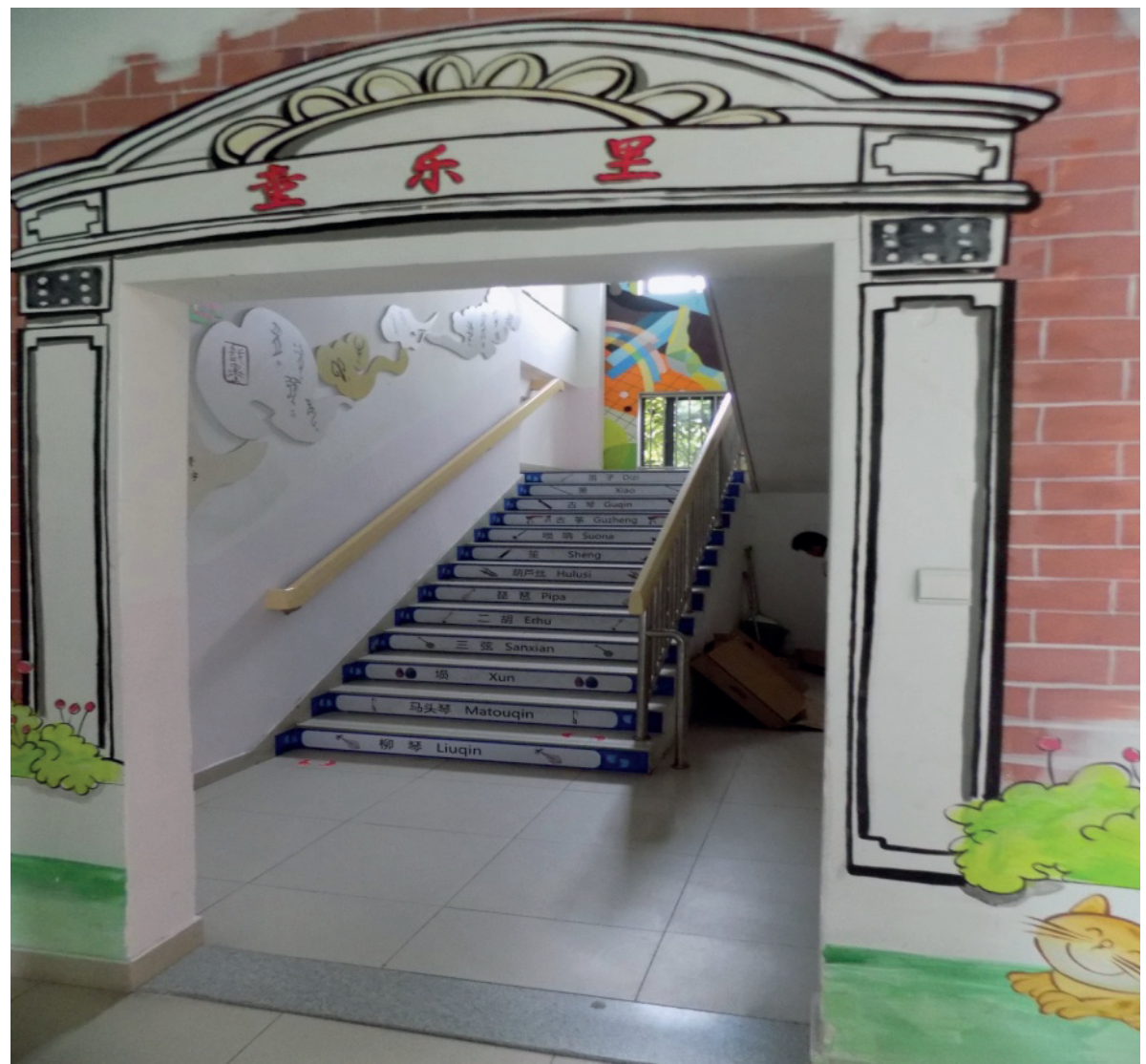

Figure 3. Stairs in a primary school in Shanghai (affiliated to the East China Normal University). Photo by Marsico, 2017

The ordinary emptiness of places like corridors and stairs have not only been transformed into tools for thinking, learning, and teaching, but also for narrating a collective history of the school, of the neighbourhood, of the Nation and therefore, for forming a specific cultural identity.

While walking into those spaces, some questions arose: how much time does a 6-year old student spend per day in the school corridors or going up and down the stairs? Maybe a total of four or five minutes per day. If this is the case, why do Chinese schools invest large amounts of money and pedagogical energy in making these passage spaces so educationally charged? There are several reasons why Chinese kindergartens and schools use corridors and stairs like this. Historically it was a political tradition of the Communist Party, which successfully used dissemination methods to encourage people in wartime. They used walls and decorations to let the public know the key ideas and values which the Party leaders hoped to achieve. Also, 
some of the schools and kindergartens have their own educational ideas. They are encouraged to have healthy bodies, explore the world, be happy to learn, be a kind person, acquire skills of cooperation, care about the community and the country, and so on. Short keywords, with good calligraphy, are exhibited on entrance gates or corridor walls, and engraved stone tablets hung in prominent places. Decorated corridors are also appealing to visitors. The entrance to the building is where visitors get their first impression of the school and should look good - this is important to the school principals and teachers and prevents them losing face.

Chinese schools are motivated to make their place look very nice, meaningful and promote an artistic and cultural atmosphere. Efforts are made to create a homely atmosphere, full of warmth and traditions. It is hoped the students feel the teachers are kind like their father and mother, and that each one of the class of 40 students' is their family. Of course, this meaning that 40 pupils belong to their whole class family is metaphoric, however, everyone in the class can use their section of corridor to show how they want to exhibit to the other class families - inter-group comparison.

\section{School ethnography}

Schools almost all over the world look like factories where long corridors with metal lockers are a means of transporting students from one classroom to another. They serve the double function of control and circulation of the students within the school territory, but they also connect the inside with the outside of the school (Marsico, Dazzani, Ristum, \& Bastos, 2015; Marsico \& Iannaccone, 2012).

In a normal size school so much space is occupied by corridors. Based on a rough estimation one could say that $30 \%$ of a typical school building is used, not for the classic learning settings (the classroom or the labs), but instead for getting people there. Thus, corridors are designed to be empty during classes and utilised under specific circumstances and at specific moments of the school activities (i.e. the entering and exiting school routine at the beginning and at the end of the day or for moving from one activity to another) (Marsico, 2018). The Chinese school corridors and stairs, instead, were not strictly intended for transport, but they were purposefully designed as spaces for informal learning

A school-based ethnography aims at achieving detailed descriptions and in-depth analyses of the structural and functional system that culturally regulates the experiences of the different actors involved (i.e. students, teachers, administrative staff, parents, etc.) (Lycke \& Hurd, 2017). 
in a formal setting. They were not just spaces to display student's art-works, as in many schools all over the world, but they offered an effective and immersive space, covered with traditional Chinese paintings depicting stories usually with moral-related meanings. By pushing a button (see the arrow bottom left side of the picture, Figure 2), an audio recording of music and voice starts and tells the story painted on the wall. Thus, while walking along the corridor, any kid can be exposed to this audio-visual storytelling and therefore learn something about the traditional Chinese culture. This is only one example of the most interesting findings of our ethnographic observations that is the multifaceted structural and functional purposes of the school borders (Marsico, 2016).

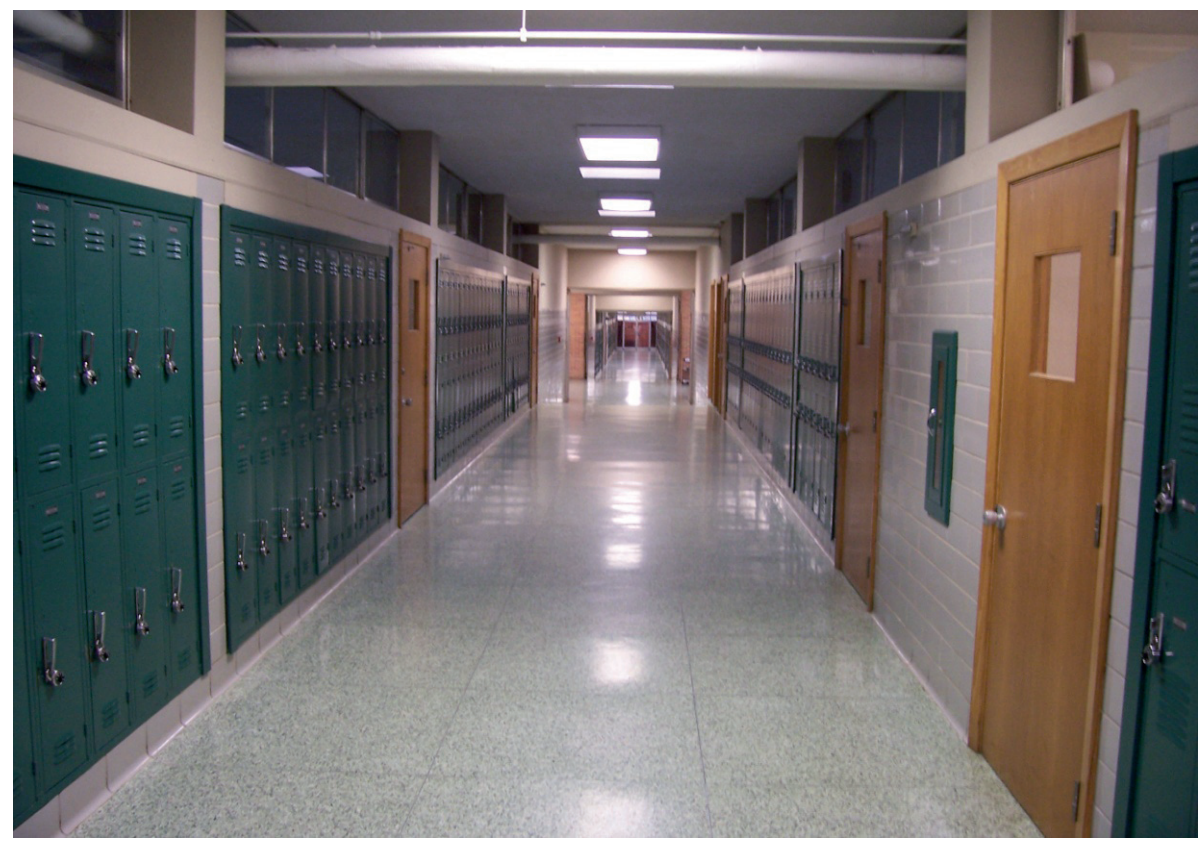

Figure 4. A hallway in the High School Main Building (Baton Rouge, Louisiana). From Wikipedia

\section{Corridors as a special case of borders/connectors}

Corridors play an important role in human spatiality and mobility. Typical examples are the corridors and tunnels in airports, train stations, and etros. Yet, even where the functions of connecting people and being areas of mobility prevail over any educational efforts in the Chinese schools, there are some other interesting social experiments going on. At Frankfurt airport, for example, the enormous artistic photos by Martin Liebscher, showing different destinations 
from all over the world, decorate the passenger tunnel (Figure 5). Thanks to these photos, every day thousands of travellers, walking to their boarding gates, enjoy this artwork, and in so doing they connect themselves with the world outside. These gigantic pictures of amazing destinations from all over the planet, amplifies the here and now of the "being on the move" traveller's identity and connects the closed airport transfer area with the external world. In the same vein, the kindergarten's painted wall links the children with the traditional Chinese culture over the years.

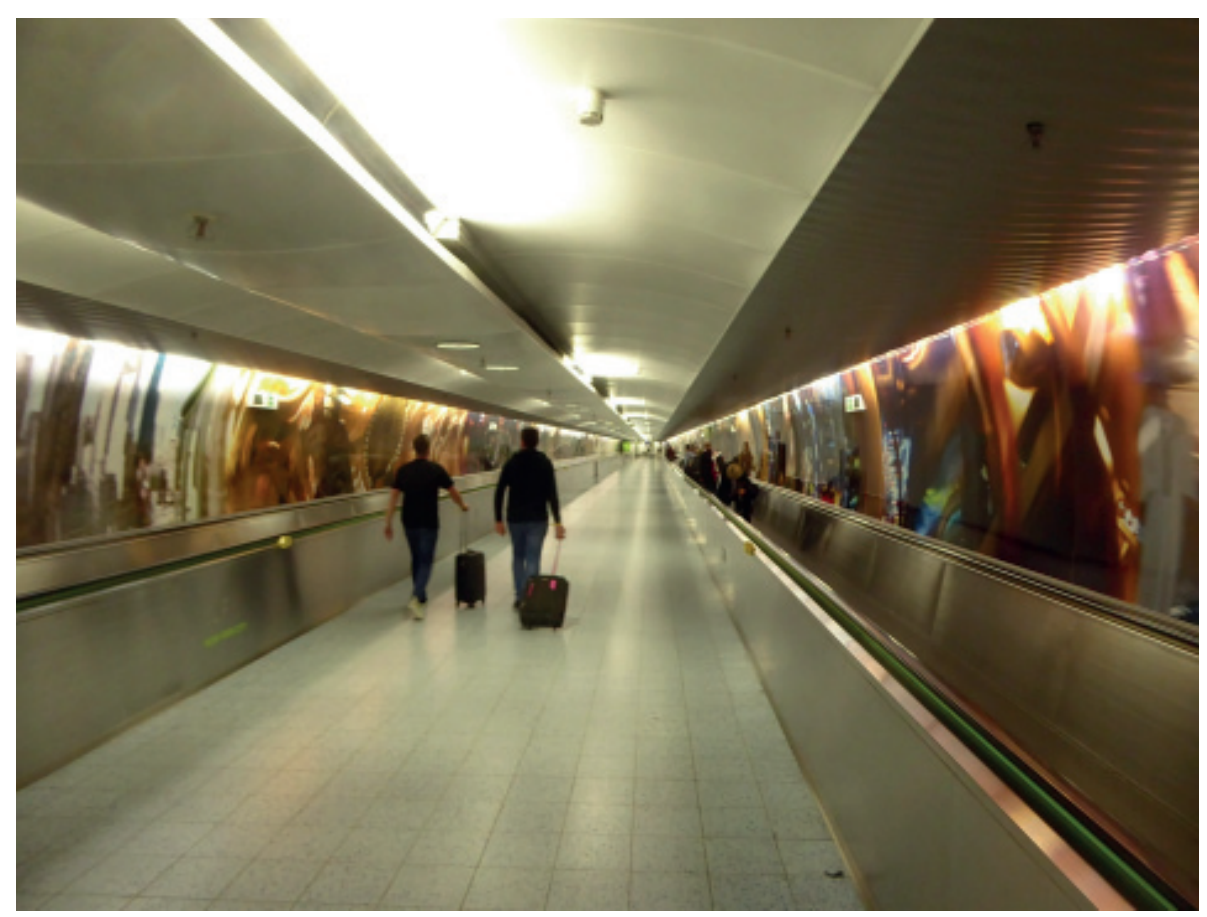

Figure 5. Passenger tunnel, Frankfurt Airport ${ }^{5}$. Photo by Valsiner, 2017

Corridors are, therefore, the connecting border zones, not only within the same physical space, but also with other geographical places and temporal dimensions. Corridors act simultaneously as connectors and separators (i.e. while they connect Terminals A and B, they also separate them) and this is because they occupy a space in between. The "betweens" is in fact, the general characteristic of any corridor.

5 https://www.frankfurt-airport.com/en/travel/transfer.detail.suffix.html/article/explore/ discover/passenger-tunnel.html 
Corridors are significant elements in other domains, such as New Urbanism. In this perspective, a corridor is an indispensable urban element that serves as a connection and a mobility between neighbourhoods and districts. According to Duany and Plater-Zyberk (1994):

Corridors include natural and man-made elements, ranging from wildlife trails to rail lines. The corridor is not the haphazardly residual space that remains outside subdivisions and shopping centers in suburbia. Rather, it is an urban element characterized by its visible continuity. It is defined by its adjacent districts and neighborhoods and provides entry to them. The corridor's location and type is determined by its technological intensity and nearby densities. Heavy rail corridors are tangent to towns and traverse the industrial districts of cities. Light rail and trolleys may occur within a boulevard at the neighborhood edge. As such, they are detailed for pedestrian use and to accommodate the frontages of buildings. Bus corridors can pass through neighborhood centers on conventional streets. All of these should be landscaped to reinforce their continuity. In low-density areas, the corridor may be the continuous green edge between neighborhoods, providing long-distance walking and bicycle trails, other recreational amenities and a continuous natural habitat. (p. xx)

The corridor acquires an even more vital feature in the Natural Landscape (Palang, 2010). Conservation Biology (Beier \& Noss, 1998; Bennett, 1999) claims that corridors provide landscape connectivity. Corridors enhance the population viability of species in habitat patches. Therefore, they are valuable conservation tools for dispersing animals in fragmented landscapes. As Cushman et al. as (2013) pointed out; the corridors allow animals to shift their geographical range in response to climate changes, to maximise the access of resources and minimising mortality risk.

\section{Ornamented corridors}

So far, we have underlined the multifaceted structural and functional purposes of the in-between zone like corridors and their simultaneous feature of dividing and connecting. Yet, the psychological reason why human beings decorate this border zone needs further elaboration. According to Valsiner (2018):

We decorate our environments. These decorations - ornaments - are not occasional "attachments" of what we haphazardly prefer to see as merely "beautifying" our life-worlds. They encode various meanings in the form of $\{A<>$ non- $A\}$ oppositions that involve inherent tension between the opposing parts within the whole. These tensions we project into the 
environments, and through that we further guide the feelings of our minds as if those were impending upon us from within our environments. By decorating ourselves and our environments we are transforming ourselves into ever new ways of being human". (p. 230)

The ways in which we decorate a space illuminates the set of meanings and values, and affects the way that we as humans project into the environment and that makes it something more than a simple place (Cornejo, Marsico, \& Valsiner, 2018). The role of ornaments is, then, to fill our peripheral sensory systems with images of cultural suggestions. This is an act of "constructive externalization - the goal of which is further feed-forward to equally constructive internalization." (Valsiner, 2018, p. 230).

The ornamented corridors as in the Chinese schools and in the Frankfurt airport (see the figures above) are culturally meaningful architectural spaces that act as psychological tools of semiotic mediation.

\section{Myths in movement: education through the periphery}

Corridors and stairs tell a story. The basis of the story is the need to move from one place to another. Yet decorating the surroundings of the people who move through is an elaboration of the base story - often a myth. For instance, Frankfurt Passenger Tunnel is all about the mythology of the "Travel", while in the examples of the Chinese schools, the myth of "Old China" or of "Science" are the most important themes. These are educational messages inserted into the environment. These messages provide guidance for personal interpretations of the world in culturally expected directions (Gupta \& Valsiner, 1996).

Corridors teach. Or - at the least - they can be viewed as "silent teaching assistants." The psychological functioning of the highly decorated school corridors is to fill our peripheral sensory systems with directive input that we experience peripherally - by passing by - as a part of general moving through. This short repeated "walking along" the corridors on a daily basis is much more of a mere transfer action. The contents and encrypted feelings of these semiotic complexes pass through the internalisation/ externalisation system of the persons. The mythological stories of the "Old China" or of the constant reminding of the passers-through of the importance of "Science" become constructively internalised by the person, and then, in turn, begins to feed forward to the pupils' learning activity in the classrooms. The decorated walls serve as catalysts in the relationships of the learners and the materials to be mastered.

To summarise - education involves the whole of the environment, not only the explicit acts of teaching-and-learning in the classroom. The whole 
secondary support structure of the teaching/learning process works in the background to keep the learners within the field. As the field is structured in a heterogeneous way, the peripherally located suggestions may become central for the learner. Implicit educational tools support the explicit efforts of educators in their everyday activity contexts.

\section{References}

Beier, P., \& Noss, R. F. (1998). Do habitat corridors provide connectivity? Conservation Biology, 12(6), 1241-1252. https://doi.org/10.1111/j.1523-1739.1998.98036.x

Bennett, A. F. (1999). Linkages in the landscape: The role of corridors and connectivity in wildlife conservation. Glang, Cambridge: IUCN.

Cornejo, C., Marsico, G., \& Valsiner, J. (Eds.) (2018). I activate you to affect me (Vol. 2), Charlotte: Information Age Publishing.

Cushman, S. A., McRae, B., Adriaensen, F., Beier, P., Shirley, M., \& Zeller, K. (2013). Biological corridors and connectivity. Key Topics in Conservation Biology, 2, 384404. https://doi.org/10.1002/9781118520178.ch21

Duany, A., \& Plater-Zyberk, E. (1994). The neighborhood, the district and the corridor. In P. Katz (Ed.), The new urbanism: Toward an architecture of community (pp. xvii-xx). New York: McGraw-Hill.

Gupta, S., \& Valsiner, J. (1996). Myths in the hearts: Implicit suggestions in the story. Paper presented at the Second Conference on Socio-Cultural Studies, Geneva, September 14, 1996.

Lycke, K. L., \& Hurd, E. (2017). Question of changing access: Who participates in school ethnographies and why? International Review of Qualitative Research, 10(3), 291-305. https://doi.org/10.1525/irqr.2017.10.3.291

Marsico, G. (2016). The borderland. Culture \& Psychology, 22(2), 206-215. https://doi.org/10.1177/1354067X15601199

Marsico, G. (2018). Development and education as crossing socio-cultural boundaries. In A. Rosa \& J. Valsiner (Eds.), The Cambridge handbook of sociocultural psychology (2nd ed., Vol. 1). Cambridge: Cambridge University Press.

Marsico, G., Dazzani, V., Ristum, M., \& de Souza Bastos, A. C. (Eds.) (2015). Educational contexts and borders through a cultural lens: Looking inside, viewing outside. Cultural Psychology of Education, 1. Geneve: Springer.

Marsico, G., \& Iannaccone, A. (2012). The work of schooling. In J. Valsiner (Ed.), The Oxford handbook of culture and psychology (pp. 830-868). New York: Oxford University Press.

Palang, H. (2010). Time boundaries and landscape change: Collective farms 19471994. European Countryside, 2(3), 169-181. https://doi.org/10.2478/v10091-010-0012-6

Valsiner, J. (2003). Upconscious processes in schooling. European Journal of School Psychology, 1(1), 43-56.

Valsiner J. (2018). Dialogical relationship between open and closed infinities. In G. Marsico \& J. Valsiner (Eds.), Beyond the mind: Cultural dynamics of the psyche (pp. 229-244). Charlotte: Information Age Publishing. 